Keio J. Med. 20: 121-126, 1971

\title{
CHOLESTEROL ESTERIFICATION FROM DIETARY FATTY ACIDS IN INTESTINAL WALL
}

\author{
YASUMASA MAJIMA \\ Institute of Nutrition, School of Medicine, Keio University, Tokyo, Japan
}

(Received for publication July 14, 1971)

\section{INTRODUCTION}

Ingested cholesterol esters normally undergoes a complete hydrolysis in the intestine. ${ }^{1}$ Free cholesterol from the hydrolysis of dietary esterified cholesterol and dietary free cholesterol as well as endogenous cholesterol excreted along with bile into the intestinal tract are esterified in the intestinal mucosa upon absorption, ${ }^{2-5}$ and the intramural esterification of absorbed cholesterol is known to be accelerated by simultaneous ingestion of free fatty acids or glycerol. ${ }^{6 / 7}$

As for the role played by dietary fatty acids in cholesterol esterification in the intestinal mucosa, a recently published study demonstrates that the fattyacid moiety of cholesterol esters emerging in the circulating plasma within 24 hours post cibum comprises largely lineoleic acid and contains only a few saturated and mono-unsaturated fatty acids even if the diet supplied is rich in saturated fatty acid content and poor in linoleic acid content; thereby suggesting a probably faster incorporation into plasma cholesterol esters of endogenous fatty acids from intramural biosynthesis than of saturated and mono-unsaturated fatty acids of dietary origin. ${ }^{8}$ Moreover, it has been reported that the fatty-acid composition of plasma cholesterol esters is only slightly affected even following ingestion of fat possessing specific fatty acid compositions.9 The study herein to be described was conducted in an attempt to clarify relationship of dietary fatty acids to cholesterol esterification in the intestinal wall or, more particularly, to determine whether and, if at all, to what extent dietary essential fatty acids and saturated fatty acids behave mutually differently in the intramural cholesterol esterification in albino rats. 


\section{EXPERIMENTAL}

A series of albino rats, all male with an average body weight of $200 \mathrm{~g}$ approx. and starved for 48 hours (supplied with water alone), were divided into 17 groups, 15 to 20 rats per group. They were assigned regimens of various labelled fatty acid or lipid contents all in the basal ration supplied in soft pellet form consisting of small amounts of starch, fat-free fishmeal, sodium chloride and water, as follows:

Group I: $2.3 \mu \mathrm{C}$ of $1-\mathrm{C}^{14}$-palmitic acid $\left(=0.92 \times 10^{5}\right.$ c.p.m.) plus $0.5 \mathrm{~g}$ of palmitic acid per animal; Group II : $4.0 \mu \mathrm{C}\left(=2.38 \times 10^{5}\right.$ c.p.m. $)$ of 1-C ${ }^{14}$-stearic

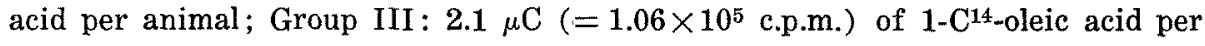
animal; Group IV : $3.6 \mu \mathrm{C}\left(=1.81 \times 10^{5}\right.$ c.p.m. $)$ of 1-C ${ }^{14}$-linoleic acid per animal; Group V: $2.3 \mu \mathrm{C}$ of $1-\mathrm{C}^{11}$-palmitic acid plus $0.3 \mathrm{~g}$ of cholesterol per animal; Group VI : $4.0 \mu \mathrm{C}$ of $1-\mathrm{C}^{14}$-stearic acid plus $0.3 \mathrm{~g}$ of cholesterol per rat; Group VII: $2.1 \mu \mathrm{C}$ of $1-\mathrm{C}^{14}$ oleic acid plus $0.3 \mathrm{~g}$ of cholesterol per rat; Group VIII : $3.6 \mu \mathrm{C}$ of 1-C ${ }^{14}$-linoleic acid plus $0.3 \mathrm{~g}$ of cholesterol per rat. Group IX thru XII received the same labelled fatty acids respectively as in Groups $V$ through VIII supplemented severally with $0.3 \mathrm{~g}$ of cholesterol palmitate, cholesterol stearate, cholesterol oleate and cholesterol linoleate. Groups XIII thru XVI were given cholesterol esters of which the carbon atom in position 1 of fatty acid is substituted with $\mathrm{C}^{14}$; Group XIII, $0.5 \mathrm{~g}$ ( $1.6 \mu \mathrm{C}=0.58 \times{ }^{5}$ c.p.m.) of cholesterol palmitate per rat; Group XIV, $0.5 \mathrm{~g}\left(2.2 \mu \mathrm{C}=1.08 \times 10^{5}\right.$ c.p.m. $)$ of cholesterol stearate per animal; Group XV, $0.5 \mathrm{~g}\left(1.2 \mu \mathrm{C}=2.90 \times 10^{5}\right.$ c.p.m. $)$ of cholesterol oleate per animal; and Group XVI, $0.5 \mathrm{~g}\left(1.8 \mu \mathrm{C}=2.14 \times 10^{5}\right.$ c.p.m.) of cholesterol linoleate per animal. The animals in Group XVIII were fed the ration supplemented with $3.1 \mu \mathrm{C}\left(=4.11 \times 10^{5}\right.$ c.p.m. $)$ of cholesterol-26-C $\mathrm{C}^{14}$ plus $0.3 \mathrm{~g}$ of cholesterol per rat.

The cholesterol esters containing $\mathrm{C}^{14}$-labelled fatty acids had been prepared by the method of synthesis described in the previous report. ${ }^{11}$

At three hours after the feeding blood samples were drawn; sera were separated; mild extraction of serum fat was performed with a methanol-ether mixture $(3: 1)$; and cholesterol esters and triglycerides were separated there from by the chromatographic procedure described previously by the author. ${ }^{10}$ The colesterol ester and triglyceride contents were determined by means of a gas G.M. counter, reading the respective specific radioactivity. 


\section{RESULTS AND DISCUSSION}

All animals receiving specified fatty acid or cholesterol regimens had displayed peak serum levels of cholesterol esters and triglycerides at 2.5 to 4.0 hours after administration (presentation of pertinent data omitted) in a preliminary experiment. In view of it blood samples were obtained at 3 hours after administration for serum assays to make the indirect assessment of lipid biosyn-

Table 1

Incorporation of various $C^{14}-$ labelled fatty acids into serum cholesterol esters and triglycerides at 3 hours after administration in albino rats, starved for 48 hours

\begin{tabular}{|c|c|c|c|}
\hline \multirow{2}{*}{ Group } & \multirow{2}{*}{ Administration } & \multicolumn{2}{|c|}{$\begin{array}{l}\text { Specific activity (each \% per } \\
100 \mathrm{mg} \text { of total fat) }\end{array}$} \\
\hline & & $\begin{array}{l}\text { Cholesterolester } \\
(\%)\end{array}$ & $\begin{array}{l}\text { Triglyceride } \\
(\%)\end{array}$ \\
\hline I & 1-C $\mathrm{C}^{14}$-palmitic acid & 0.01 & 4.9 \\
\hline II & 1- $\mathrm{C}^{14}$-stearic acid & 0.2 & 4.3 \\
\hline III & 1- $\mathrm{C}^{14}$-oleic acid & 0.1 & 7.2 \\
\hline IV & 1-C $\mathrm{C}^{4}$-linoleic acid & 0.2 & 3.7 \\
\hline V & 1-C ${ }^{14}$-palmitic acid +cholesterol & 0.4 & 2.9 \\
\hline $\mathrm{VI}$ & 1- $\mathrm{C}^{\mathrm{H}}$-stearic acid + cholesterol & 0.5 & 3.6 \\
\hline VII & 1-C $\mathrm{C}^{14}$-oleic acid +cholesterol & 1.1 & 5.4 \\
\hline VIII & 1- $\mathrm{C}^{14}$-linoleic acid + cholesterol & 0.4 & 4.0 \\
\hline $\mathbb{X}$ & 1- $\mathrm{C}^{14}$-palmitic acid $+\begin{array}{c}\text { cholesterol } \\
\text {-palmitate }\end{array}$ & 0.5 & 2.8 \\
\hline$x$ & $1-\mathrm{C}^{14}$-stearic acid $+\underset{\text {-stearate }}{\text { cholesterol }}$ & 0.7 & 5.2 \\
\hline $\mathrm{XI}$ & $1-\mathrm{C}^{\mathrm{H}}$-oleic acid $+\underset{\text {-oleate }}{\text { cholesterol }}$ & 1.2 & 7.0 \\
\hline XII & 1-C $\mathrm{C}^{14}$-linoleic acid $+{ }_{\text {-linoleate }}^{\text {cholesterol }}$ & 0.2 & 2.4 \\
\hline 奴 & Cholesterol-1- $\mathrm{C}^{14}$ palmitate & 0.7 & 2.8 \\
\hline XIV & Cholesterol-1-C $\mathrm{C}^{14}$-stearate & 0.8 & 1.9 \\
\hline$X V$ & Cholesterol-1-C $\mathrm{C}^{14}$-oleate & 1.0 & 4.1 \\
\hline XVI & Cholesterol-1-C $\mathrm{C}^{14}$ limoleate & 0.9 & 2.7 \\
\hline XVII & Cholesterol-26- $\mathrm{C}^{14}$ & 0.4 & 0.1 \\
\hline
\end{tabular}


thesis in the intestinal wall in the study herein described.

The serum levels of cholesterol esters and triglycerides at 3 hours after administration of specified fatty acids or of their mixtures in 48-hour-starved albino rats were determined to be in all cases from 10 to $15 \mathrm{mg}$ approx. per $100 \mathrm{ml}$ and from about 25 to $40 \mathrm{mg}$ per $100 \mathrm{ml}$ respectively (presentation of data omitted). Table 1 shows the average specific radioactivities of serum cholesterol esters and triglycerides.

As can be seen, the animals in Group I, II, III and IV receiving fatty acids alone exhibited notably low specific activity values for cholesterol esters $(0.01$ to $0.2 \%$ ), which being as low as less than one-nineteenth those for triglycerides.

The rats given fatty acids along with cholesterol simultaneously (Groups $\mathrm{V}$ thru VIII) showed slightly greater specific activity values for cholesterol esters $(0.4$ to $1.1 \%)$, and such tendency was prominent with the oleic acid plus cholesterol regimen given to the rats in Group VII. The values, in general, were considerably low $(1 / 10$ to $1 / 5)$ in all cases in comparison with those determined for triglycerides, however.

Animals fed fatty acids together with cholesterol esters containing corresponding fatty acids (Groups IX thru XII) all displayed specific radioactivity values for cholesterol esters which were practically comparable to those observed in Groups V, VI, VII, and VIII, i.e. 0.2 to $1.2 \%$. The animals in Group XI fed oleic acid plus cholesterol oleate showed a particularly high specific activity on the average. The values, however, were again somewhat lower $(1 / 12$ to $1 / 6)$ as compared with those determined for triglycerides.

Specific activity values for serum cholesterol esters modestly greater $(0.7$ to $1.0 \%$ ) than those in the foregoing groups were observed in the animals of Groups XIII through XVI which had received cholesterol esters alone, and their ratio to the observed values for serum triglycerides were also comparatively greater $(1 / 4$ to $1 / 2)$ although they failed to exceed $1 / 2$ of the latter.

The animals of Group XVII which were fed free cholesterol alone showed fairly low specific radioactivity for serum cholesterol esters.

The results observed in Groups I through IV and in Group XVII inferred that esterification of cholesterol upon reabsorption after excretion along with bile into the intestinal tract takes place not to any remarkable extent in the intestinal wall and that fatty acids occurring in the circulating plasma take part in the intramural esterification of absorbed cholesterol while cholesterol contained in the plasma scarcely participates in it. It was also deduced to be highly probable from the observation of rather modest esterification of cholesterol in the intestinal mucosa that absorbed cholesterol may be actively esterified in the 
liver under normal conditions.

From the findings obtained in Groups $\mathrm{V}$ throùgh VIII and in Group XVII, it is evident that all dietary fatty acids take uniform part in esterification of dietary cholesterol in the intestinal wall although the amounts of participating dietary fatty acids are relatively small. The findings obtained in Group IX through XII, furthermore, indicate that the fatty acids in dietary cholesterol esters are displaced with dietary free fatty acids in the intramural process of reesterification of free cholesterol originating from dietary cholestrol esters. The results in Groups XIII through XVI confirm the observations made in the previous study that dietary cholesterol esters were utilized in the body only in small part as cholesterol esters and that the fatty acids liberated from hydrolysis of ingested cholesterol esters were destined in greater part for use as triglycerides and so forth.

\section{SUMMARY}

Serum assays for specific radioactivity of cholesterol esters and triglycerides were performed with blood samples drawn from albino rats 3 hours after administration of specified fatty acids and or free cholesterol or cholesterol esters labelled with radioactive $\mathrm{C}^{14}$ upon starvation for 48 hours. The labelled fatty acids used included palmitic acid, stearic acid, oleic acid and linoleic acid. The results may lead to the following conclusions:

1. Cholesterol esters produced in the intestinal wall from dietary cholesterol or from cholesterol originating from ingested cholesterol esters are in limited quantities. Both dietary fatty acids and plasma fatty acids take part in the cholesterol esterification which proceeds in the intestinal wall whereas neither the cholesterol excreted in the intestinal tract nor the plasma cholesterol participates to any remarkable degree in the intramural esterification.

2. In the biosynthetic process of re-esterification of cholesterol derived from dietary cholesterol esters that takes place in the intestinal wall, the fattyacid components of ingested cholesterol esters are replaced with simultaneously administered (dietary) fatty acids.

\section{REFERENCES}

1. Swell, L. Batter, T. A., Field, H. Jr., and Treadwell, C. R. (1955) Absorption of dietary cholesterol ester. Am. J. Physiol. 180: 129.

2. Daskalakis, E. G. and Chaikoff, I. L. (1955) The significance of esterification in the absorption of cholesterol from the intestine. Arch. Biochem. Biophys. 58: 373. 
3. Swell, L. E., Trout, E. C., Jr., Hopper, J. R., Field, H., Jr., and Treadwell, C. R. (1958) Mechanism of cholesterol absorption I. Endogenous dilution and esterification of fed cholesterol-4-C14. J. Biol. Chem. 232: 1.

4. Swell, L., Trout, E. C., Jr., Hopper, J. R., Field, H., Jr., and Treadwell, C. R. (1958) Mechanism of cholesterol absorption. II. Change in free and esterified cholesterol pools of mucosa after feeding cholesterol-4-C14. J. Biol. Chem. 233: 49.

5. Swell, L. E., Trout, E. C., Jr., Field, H., Jr., and Treadwell, C. R. (1958) The role of lymph cholesterol in the regulation of endogenous cholesterol and cholesterol ester synthesis. J. Biol. Chem. 230: 631.

6. Vohoung, G. V., Fawal, I., and Treadwell, C. R. (1957) Factors facilitating cholesterol absorption from the intestine via lymphatic pathways. Am. J. physiol. 188: 342 .

7. Sylven, C. and Borgström, B. (1968) Absorption and lymphatic transport of cholesterol in the rat. J. Lipid. Res. 9: 596.

8. Nestel, P. J. and Couzens, E. A. (1966) Influence of diet on the composition of plasma cholesterol esters in Man. J. Lipid. Res. 7: 487.

9. Kayden, H. J., Karmen, A., and Dumont, A. (1963) Alterations in the fatty acid composition of human lymph and serum lipoproteins by single feedings. J. Clin. Invest. 42: 1373.

10. Majima, Y. and Kurihara, F. (1963) Separation and determination of fat. J. Jap. Soc. Food Nutrition. 16: 280. (in Japanese)

11. Majima, Y. (1970) Metabolism of fatty acids in cholestrol ester. Keio. J. Med. 19: 151. 